\title{
Clinical trials in developing countries: risk or opportunity?
}

\author{
"The globalization of the conduct of clinical trials is already an established reality, with increasing numbers of investigators, \\ sites and trial subjects in countries outside Western Europe and the USA."
}

The development of evidence-based medicine and requirements of regulatory agencies are leading to an increased need for larger numbers of patients to be included in trials supporting marketing authorization applications (MAAs). As a consequence, there is high pressure from pharmaceutical companies on countries or regions where patients are available. The globalization of the conduct of clinical trials is already an established reality, with increasing numbers of investigators, sites and trial subjects in countries outside Western Europe and the USA. This may raise ethical and regulatory issues depending on how the trials are designed, performed and analyzed.

In pivotal clinical trials submitted in MAAs to the EMEA [101] between 2005 and 2008, approximately $70 \%$ of subjects were recruited in European countries and the USA combined and close to $30 \%$ in the other regions of the world. The other regions were represented predominantly by Eastern European countries outside of the EU (e.g., Commonwealth of Independent States), Latin America and the Asia-Pacific region. Fewer trials took place in Africa and the Middle-East.

\section{"Lower cost can raise concern where it is dependent on great poverty of the society in which the clinical trial is conducted."}

The reasons for trials to be performed in third-world countries are multiple. They can be economical due to the reduced cost of investigators and facilities and greater availability of patients with shorter recruitment time. In particular, there are more children in developing countries. It may also be easier to find treatmentnaive subjects and the disease studied may be more prevalent or only found in those countries. Locally, physicians may be eager to get access to research, perhaps also due to financial reasons, as well as eager to access medicines that would otherwise remain unavailable to their patients. Lower cost can raise concern where it is dependent on great poverty of the society in which the clinical trial is conducted. The interest from industry in these regions may be due to the large patient populations, emerging economies and health resources, with a view to increasing markets.

Unfortunately, less rigorous regulatory or ethical frameworks may also be factors and the perception that these could be major drivers is a particular concern.

The issue of informed consent in third-world countries has been extensively debated in the literature [1]. The major issue remains the contrast between the infrangible principle of the autonomy of the subject and the inducements that a trial brings about. There might be a need to adapt the process of informed consent to take stock of cultural differences, without ever accepting, however, that the individual is not consulted and deciding. For example, in some countries, the head of the community may make decisions that include those affecting individuals: women and children would not be expected or allowed to make a decision for themselves. This is not an easy issue to solve. Information needs be appropriate, understandable and fair. Additionally, the level of education of parents may prevent them from making an informed choice for their children. Children and pregnant women represent a vulnerable population with respect to clinical trials, especially when the trials are performed in third-world countries.

Medical care and access to health is likely to differ significantly in those countries. For example, the standard of care is likely to be different from that of European countries. Access to care and treatment in these countries through trials may represent a significant inducement. As a

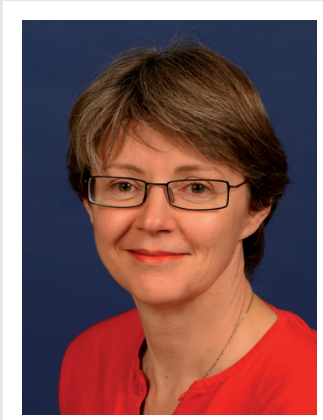

Agnès Saint Raymond Author for correspondence European Medicines Agency, 7 Westferry Circus, Canary

Wharf, London EI4 4HB, UK Tel.: +442075237017

Fax: +44 2075237040

E-mail: agnes.saint-raymond

@emea.europa.eu

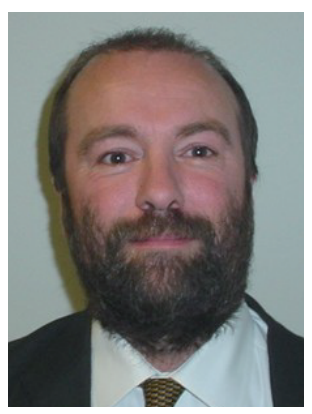

Fergus Sweeney

European Medicines Agency,

7 Westferry Circus, Canary

Wharf, London EI4 4HB, UK 
consequence, patients and investigators may be more compliant with study requirements. This is not acceptable without the protection of a well-established, reliable ethical framework.

The EU pharmaceutical legislation sets out scientific and ethical standards for the conduct of all clinical trials to be included in a MAA [102,103]. The same legislation requires that all clinical trials, whether complete or discontinued, are included in the MAA and that all meet these ethical standards. However, the pharmaceutical legislation of the EU does not dictate where clinical trials should take place. It is only necessary that extrapolation of results to the EU population is possible from the scientific point of view.

In the EU, legal texts such as the Directive 2001/83/EC and its Annex I, as amended, set out the required contents of a MAA and specify the standards that must be met [102] The Annex I requires that clinical trials performed in third-world countries and included in a MAA to the EU are performed to ethical standards equivalent to those of the EU clinical trial directive 2001/20/EC, following ethical principles such as those in the Declaration of Helsinki and local requirements [104]. Further ethical and technical requirements are set out in guidance on good clinical practice CPMP/ICH/135/95 and guidelines from the International Conference on Harmonization, and include specific issues relating to trials in pediatric or elderly populations or specific therapeutic areas [105]. The EU has also published guidance on ethics [106].

In choosing to perform their clinical trials in emerging countries, sponsors have a responsibility to ensure that the trials are ethically and scientifically valid, respect local requirements and can address any shortcoming in investigator training or experience, or in the capacity of local ethics committees or regulatory processes. One proposal has been to double-check with an EU Ethics Committee that a protocol would be acceptable by the EU standards to provide reassurance on this issue.

In view of the increasing number of such trials and to address the concerns, the frequency of good clinical practice inspections in these countries have increased significantly, in particular over the last 3 years. The local regulators are contacted on the occasion of each inspection with a view to their participation as observers - a capacity-building opportunity. Such inspections by EU regulators at the time of MAA have limitations. They can only confirm how the trial was conducted after it has been completed and can only visit a very small fraction of the total investigator sites involved. Additionally, education of all those involved in trials is paramount as it may prevent unethical approaches. This is currently performed through cooperation on capacity building with the WHO, EU member states, competent authorities and the EMEA.

Once the trial is completed, publication must be ensured that includes negative trials, as such information is useful. This also avoids repeating unnecessary trials and is an ethical duty vis-à-vis the patients included in the trials.

\section{"In choosing to perform their clinical trials in emerging countries, sponsors have a responsibility to ensure that the trials are ethically and scientifically valid, respect local requirements and can address any shortcoming in investigator training or experience..."}

When major violations have occurred in a trial, publication is generally considered unethical, as outlined, for example, by the Declaration of Helsinki, to avoid promoting unethical approaches. There is, however, the risk of 'hiding' such trials, which leads to other negative consequences: patients who were included do not get the chance to be recognized for their contribution and there is a risk of repeating the same mistakes through lack of education. Transparency for these trials, along with clear warnings and explanations, is recommended.

The new legal basis for systematic publication of trials (including their results) performed in the EU in adults and all those included in a pediatric investigation plan, wherever they take place, will provide full transparency, including those trials that were never published [107]. This is in line with similar transparency measures taken at the international level, for example by the US FDA, the International Conference of Medical Journal Editors and the WHO.

Taking into consideration the increased number of trials and the concerns, in January 2009, the EMEA published a strategy paper on 'acceptance of clinical trials conducted in third-world countries for marketing authorization applications' [108]. A working group is now developing the action areas set out in this strategy and the EMEA will report further on this as the implementation develops. 
Developing clinical research in third-world countries will provide opportunities to patients and physicians by giving them access to medicines and care and the benefits of research; however, strong regulatory and ethical frameworks are necessary to protect very vulnerable patients, including pregnant women and children.

\section{Disclosure}

The views presented in this editorial are those of the authors and should not be understood or quoted as being made on behalf of the EMEA and/or its scientific Committees.

\section{Financial \& competing interests disclosure}

Both Fergus Sweeney and Agnès Saint Raymond are fulltime employees of the EMEA. The authors have no other relevant affiliations or financial involvement with any organization or entity with a financial interest in or financial conflict with the subject matter or materials discussed in the manuscript. This includes employment, consultancies, honoraria, stock ownership or options, expert testimony, grants or patents received or pending, or royalties.

No writing assistance was utilized in the production of this manuscript.

\section{Bibliography}

1 Angell M. The ethics of clinical research in the Third World. N. Engl. J. Med. 337(12), 847-849 (1997).

\section{- Websites}

101 EMEA website www.emea.europa.eu

102 Directive 2001/83/EC of the European Parliament and of the Council of 6 November 2001 on the Community code relating to medicinal products for human use. Consolidated version: 30th December 2008 http://ec.europa.eu/enterprise/ pharmaceuticals/eudralex/vol-1/ dir_2001_83_cons/dir2001_83_ cons_20081230_en.pdf (Accessed 10 August 2009)

103 Regulation (EC) No 726/2004 of the European Parliament and of the Council of 31 March 2004 laying down Community procedures for the authorisation and supervision of medicinal products for human and veterinary use and establishing a EMEA Consolidated version: 20 April 2009 http://ec.europa.eu/enterprise/ pharmaceuticals/eudralex/vol-1/ reg_2004_726_cons/reg_2004 _726_cons_en.pdf

(Accessed 10 August 2009)

104 Directive 2001/20/EC of the European Parliament and of the Council of 4 April 2001 on the approximation of the laws, regulations and administrative provisions of the Member States relating to the implementation of good clinical practice in the conduct of clinical trials on medicinal products for human use, as amended.

Consolided version: 30 December 2008

http://ec.europa.eu/enterprise/

pharmaceuticals/eudralex/vol-1/ dir_2001_20/dir_2001_20_en.pdf

(Accessed 10 August 2009)

105 Guidelines on good clinical practice ICH E6 (CPMP/ICH/135/95).

Consolidated guideline www.emea.europa.eu/pdfs/human/ ich/013595en.pdf

(Accessed 10 August 2009)
106 Ethical considerations for clinical trials on medicinal products conducted with the paediatric population http://ec.europa.eu/enterprise/ pharmaceuticals/eudralex/vol-10/ethical_ considerations.pdf (Accessed 10 August 2009)

107 Regulation (EC) No 1901/2006 of the European Parliament and of the Council of 26 December 2006 on medicinal products for paediatric use and amending Regulation (EEC) No 1768/92, Directive 2001/20/EC, Directive 2001/83/EC and Regulation (EC)

No $726 / 2004$, as amended http://ec.europa.eu/enterprise/ pharmaceuticals/eudralex/vol-1/ reg_2006_1901/reg_2006_1901_en.pdf (Accessed 10 August 2009)

108 EMEA strategy paper. Acceptance of clinical trials conducted in third world countries, for evaluation in Marketing Authorisation Applications. Doc. Ref. EMEA/228067/2008, 5 December 2008 www.emea.europa.eu/Inspections/ docs/22806708en.pdf

(Accessed 10 August 2009) 